\title{
AVENTURAS COM A ESCRITA NO ENSINO MÉDIO: A retextualização como proposta de produção textual
}

Keyla Silva Rabêlo(*)

\section{INTRODUÇÃO}

Este artigo traz os resultados encontrados na pesquisa realizada sobre práticas de retextualização nas aulas de língua portuguesa. Os textos escolhidos para compor o corpus da pesquisa são resultado de propostas de escrita lançadas em uma turma de segundo ano do ensino técnico integrado ao ensino médio do Instituto Federal de Educação, Ciência e Tecnologia da Bahia (IFBA),campus Eunápolis.

O principal objetivo foi estudar como se instauram as políticas de escrita no âmbito escolar com a valorização de uma prática ancorada no estudo de gêneros textuais diversos - o ir além do texto dissertativo-argumentativo, prática de escrita muito comum e privilegiada no ensino médio - e como isso pode redimensionar o ensino de língua e potencializar o desenvolvimento do nível de linguagem dos alunos, principalmente no que se refere aos efeitos de sentidos que serão gerados em suas respectivas produções textuais.

Nesse sentido, planejamos uma proposta voltada para a prática de retextualização do texto literário - Dom Casmurro, de Machado de Assis - na qual os alunos foram convidados a experimentar as múltiplas possibilidades de escrita desse texto-base a partir de uma série de atividades organizadas a partir do modelo de sequência didática (SD inspirado em autores como Zabala (1998) e Schneuwly, Dolz, Noverraz (2004). Zabala (1998) conceitua a SD como “[...] conjunto de atividades ordenadas, estruturadas e articuladas para a realização de certos objetivos educacionais que têm um princípio e um fim conhecidos tanto pelo professor como pelos alunos"(ZABALA, 1998, p. 18).

Coerente com o exposto e com a natureza da pesquisa, criamos percursos pelos quais pudéssemos ir ao encontro de informações e de textos que nos permitissem compor o debate necessário. Iniciando pelo percurso que nos levaria aos textos, partimos do pressuposto de que o processo de produção textual, no quadro das teorias interacionistas da linguagem, é concebido como atividade interacional de sujeitos sociais, tendo em vista a realização de determinados fins $(\mathrm{KOCH}$,

\footnotetext{
${ }^{(*)}$ Doutoranda em Língua Portuguesa (UERJ) e Mestre em Educação pela Universidade Federal da Bahia. Instituto de Educação, Ciência e Tecnologia da Bahia, IFBA, EUNÁPOLIS. E-mail: keurabelo@yahoo.com.br.
} 
2007, p. 7), concepção também defendida por Koch (2006), Geraldi (1997), Koch e Elias (2010) e Orlandi (2012).

É nessa perspectiva que a proposta da pesquisa traz estudos que articulam as políticas de escrita adotadas pela escola na contemporaneidade - o que ensina, quando se ensina, para que $e$ para quem se ensina - e os efeitos de sentido que estas provocam na produção textual dos alunos do ensino médio.

\section{O TEXTO NA SALA DE AULA: ALGUMAS REFLEXÕES}

Nesta seção, analisaremos algumas situações que o texto, como movimento de escrita, levou para dentro da sala de aula e o que isso significou para a prática pedagógica sobre a linguagem.

Geraldi (2010, p. 124) faz uma interessante observação sobre esse caráter dinâmico da prática sobre a linguagem:

Há muito para refletir sobre a linguagem e sobre o funcionamento da língua portuguesa, de modo a desenvolver a competência linguística dos já falantes da língua, permitindo-lhes um convívio salutar com textos e com a observação dos recursos expressivos postos a funcionar nos textos. Muito mais do que descrever, trata-se de usar os recursos expressivos. Muito mais do que classificar, trata-se de perceber relações de similitude e diferença.

À luz de uma concepção sociocognitiva e interacional da linguagem, nossas análises trouxeram o texto para o cerne da discussão e, por isso, empenhamo-nos em tratá-lo como o próprio lugar da interação e os interlocutores como sujeitos ativos, empenhados dialogicamente na produção de sentidos. (KOCH; ELIAS, 2010, p. 10)

Assim, durante o processamento textual os alunos mobilizaram vários sistemas de conhecimento. Esses conhecimentos $(\mathrm{KOCH}, 2010)$ apresentam-se da seguinte forma:

Conhecimento linguístico: refere-se ao conhecimento da ortografia, da gramática e do léxico de sua língua.

Exemplo: a seleção vocabular feita pelos alunos para obter o objetivo pretendido em suas produções textuais.

Conhecimento enciclopédico: refere-se ao conhecimento do mundo que se encontra em nossa memória.

Exemplo: o uso, na HQ, do termo "partiu com o bonde" só terá sentido para seu interlocutor se este possuir conhecimento sobre o significado da expressão no contexto em que foi empregado. 
Conhecimento de textos: refere-se ao conhecimento que o produtor possui sobre as práticas comunicativas, levando em conta elementos que entram em sua composição (modo de organização), além de aspectos do conteúdo, estilo, função e suporte de veiculação.

Exemplo: Os alunos demonstraram conhecimento de todos esses aspectos quando produziram cada um dos textos aqui apresentados (poemas estruturados em versos e estrofes; H.Q organizada em quadros, falas localizadas em balões adequados às suas formas de uso e, ainda, a Literatura de cordel em que notamos a preocupação dos alunos com não só o modo organizacional, como também com a musicalidade/ritmo do texto).

Conhecimentos interacionais: configura na escrita a sua intenção quer seja ao determinar a quantidade de informação necessária para que o leitor seja capaz de construir o objetivo de produção do texto, quer seja ao selecionar a variação linguística adequada à situação de interação ou, até mesmo, à adequação do gênero à situação comunicativa.

Exemplo: a variação linguística adotada pelos alunos que produziram o artigo científico não foi a mesma utilizada pelos alunos que produziram a Literatura de Cordel. E por que essa escolha entre uma forma ou outra dos modos de dizer? Os alunos levaram em conta o movimento próprio da linguagem que considera o contexto de produção e, consequentemente, o que se diz, onde se diz, como se diz e a quem se diz.

Outro aspecto que não podemos deixar de mencionar aqui o fator da intertextualidade, a presença de um texto ou mais de um em outros textos. Sobre o assunto, Bazerman (2011, p. 25) afirma:

A intertextualidade frequentemente procura criar uma compreensão compartilhada sobre o que foi dito anteriormente e a situação atual como se apresenta. Isto é, as referências intertextuais tentam estabelecer os fatos sociais sobre os quais o escritor tenta fazer uma nova afirmação.

Postas essas considerações, temos que concordar com Geraldi (2010, p. 169) quando ele nos diz que ensinar a escrever obriga o professor a criar as condições para que determinados processos se desenvolvam sem implantá-los diretamente. Sugere que o professor precisa inverter os papéis:

[...] trata-se de uma mudança de posição do professor, do leitor-corretor para o papel de mediador do processo de aprendizagem, e por isso mesmo para o papel de co-enunciador dos textos dos seus alunos. (GERALDI, 2010, p. 170).

A escola não deve, pois, temer a presença do texto na sala de aula, uma vez que ele possibilita, como defendemos a todo tempo, vivências reais da prática de linguagem. É aproveitar as brechas intercomunicativas, no olhar de Martins (2001, p. 98), é o mínimo que a escola tem a fazer. 


\section{A ESCRITA EM ATA TEMPERATURA: A EXPERIÊNCIA COM OS ALUNOS}

Nesta seção, serão apresentadas as atividades de produção escrita realizadas com os alunos das turmas de $2^{\circ}$ ano a partir da proposta de retextualização, como também toda sua sistematização. antes, porém, faz-se necessário enfatizarmos que inúmeros são os equívocos que se materializaram em ações realizadas em sala de aula, como, por exemplo, o ensino centrado no código, produções textuais dos alunos sem interlocuções reais ou propostas de reescrita.

Na verdade, esses equívocos enquadram-se, perfeitamente, naquilo que Faraco (1984, p. 1923), denominou de as sete pragas do ensino de Português, apresentadas a seguir:

$\mathbf{1}^{\mathbf{a}}$ praga: Leitura não compreensiva: [...] incapacidade [...] de entender um texto e de analisá-lo criticamente;

$\mathbf{2}^{\mathbf{a}}$ praga: Textos chatos; todo conjunto de textos desligados da realidade;

$3^{\text {a }}$ praga: Redações-Tortura: exigências para que o aluno escreva sem lhe dar as condições para tal;

$4^{\text {a }}$ praga: Gramática-confusão: ensino de língua exclusivamente focado no estudo da teoria gramatical (no código);

$\mathbf{5}^{\mathbf{a}}$ praga: Conteúdos programáticos inúteis: seleção baseada nas gramáticas tradicionais, além de defasados, inadequados às faixas etárias;

$6^{\text {a }}$ praga: Estratégias inadequadas: correções de textos centradas no erro (desvios gramaticais), ortografia ensinada por regras ou por preenchimento de lacunas e o estudo através das listas (listas de verbos, de conjunções, classificações das classes gramaticais etc.);

$7^{a}$ praga: Literatura-biografia: estudo voltado apenas para coleta de dados biográficos dos autores e suas obras.

Como é incômodo perceber o quão nossa prática, por muitas vezes, é (ou foi em alguma época) afetada por essas pragas e o ensino de língua portuguesa foi um ensino vazio e desrespeitoso, pois, certamente, muitas vozes e escritas foram silenciadas o que torna este gesto (o de ensinar no vazio) politicamente mais grave, uma vez que as práticas sociais que poderiam ser mediadas por aquelas vozes e textos foram desconsideradas no processo de ensino-aprendizagem da língua.

Com o intuito de assegurar os objetivos previstos na pesquisa - ampliar a discussão sobre políticas de escrita no âmbito escolar, no que diz respeito à produção escrita de texto no ensino médio e os reflexos que elas produzem no desenvolvimento dos alunos com relação a essa unidade do ensino de língua portuguesa - pensamos em uma metodologia que fosse capaz de pensar em uma 
prática de produção textual que, além de desempenhar uma função social, possibilitasse ao aluno a sua emancipação enquanto cidadão.

Para tanto, partimos da tese defendida por Schnewly (1994 apud MACHADO, A., 2010, p. 150) quando diz que, nas atividades de linguagem, os gêneros se constituem como verdadeiras ferramentas semióticas complexas que nos permitem a produção e a compreensão de textos.

Defende-se, como visto, que o ensino de produção e compreensão de texto deve centrar-se no ensino de gêneros, justifica-se, então, trazer para a pesquisa não só a reflexão sobre o que a escola tem proporcionado aos alunos como práticas de escrita, mas também apresentar uma experiência de estudo de gêneros que permita tanto ao professor quanto ao aluno a compreensão em torno do objeto que foi ensinado, sua importância, como prática social, além de servir como orientação para possíveis intervenções didáticas, quando necessário.

Como já anunciado no início desta seção, muitos são os equívocos cometidos por nós ao longo de nossa prática docente. Trazemos para reflexão um equívoco bastante presente em nossas ações: a prática de uma educação literária tratada como educação bancária. Sobre educação bancária, Leahy (1999, p. 99) faz a seguinte observação:

Uma pedagogia bancária não permite que as vozes dos aprendizes sejam genuinamente ouvidas, banindo o aprendizado ativo das salas de aula. De forma bancária, o conhecimento é raramente construído através da reflexão e do diálogo.

De fato, a educação literária tal como muitas vezes é tratada não leva ao conhecimento do objeto estudado. A preocupação, muitas vezes, centra-se em pontos considerados chaves: o período em que a escola literária aconteceu, as principais obras e autores, além de algumas sinalizações sobre seu contexto histórico e político. Nega-se ao aluno, em prol de uma educação autoritária, o direito de ultrapassar os limites estabelecidos, de experimentar a desestabilização, o desconforto e o estado de transgressão que o texto literário é capaz de provocar. Vejamos o que Colomer (2007, p. 25) fala sobre a questão:

O conhecimento sobre o texto se achava deslocado pelo conhecimento do contexto-biografia do autor, o movimento artístico, o período sócio-histórico, etc., - e por avaliações críticas que pareciam indiscutíveis, mas que se revelavam historicamente condicionadas. Em definitivo, os alunos deveriam recordar o que haviam lido ou ouvido sobre as obras sem que houvesse tido necessidade de aprofundar-se em sua leitura.

Como fazer, então, para desfazer esse equívoco e tecer outros fios que possam conduzir a uma prática mais eficiente e respeitosa, ou seja, como oferecer ao aluno o letramento literário? Os velhos costumes devem ser abandonados, mas de que forma? Encontramos, mais uma vez, em 
Leahy (1999, p. 92), indicativos de uma possível chave que sirva de resposta para esse mistério: a educação literária deve acontecer como um triângulo literário:

[...] O uso da literatura é essencial no processo de educar sujeitos sociais, por se tratar de um assunto composto da combinação assimétrica de estudos linguísticos, culturais e sociais. Cada mudança de ápice desse triângulo indica uma mudança de ênfase em alguma característica cultural, política e pedagógica de um grupo social. Considerando seu caráter interdisciplinar, a educação literária é uma disciplina que cruza fronteiras (border-crossing), e esse é justamente seu papel principal na criação de uma consciência e de um saber político-social.

Nessa perspectiva, pensamos em uma proposta de educação literária que respondesse a esses anseios, que desse movimento aos eixos do triângulo (arte-palavra-sociedade) e que pudesse se mostrar como um instrumento de conscientização, prazer, liberdade e diálogo. (LEAHY, 1999, p. 93)

O corpus da pesquisa começava a tomar forma: uniríamos a ponta de dois fios: da educação literária e da educação linguística, isso e aquilo e não ou isso ou aquilo.

A atividade pensada para a turma do $2^{\circ}$ ano levou em consideração as possibilidades de metamorfose do texto ou, nas palavras de Marcuschi (2007a), atividades de retextualização. Optei por uma transposição entre gêneros escritos, já que é a escrita o objeto de estudo.

O texto gênese usado como motivação para a produção de outros textos foi o romance Dom Casmurro, uma das obras mais emblemáticas de Machado de Assis. A metamorfose aconteceria não em sua substância - enredo, personagens, tempo, espaço -, mas, sim, em sua forma - romance. poema, música, literatura de cordel, carta, história em quadrinhos, jornal, revista, foram algumas das possibilidades oferecidas aos alunos. A forma variaria e, face às especificidades, haveria uma filtragem quanto aos aspectos invariantes, em outras palavras, seria a adequação ao gênero.

Essa proposta foi assim pensada com o objetivo de levar os alunos, organizados em grupos compostos por três componentes, a desenvolverem a capacidade, nesse processo de produção textual, de moldar a linguagem em texto-como-gênero. (KRESS, 2003, p. 87 apud MARCUSCHI, 2011, p. 24).

Tomamos como "desenvolvimento da capacidade" os pressupostos teóricos de Vygotsky (1984), quando o pesquisador, para falar sobre a aprendizagem, estabelece relações entre o que ele chamou de nível de desenvolvimento real e nível de desenvolvimento proximal. O primeiro engloba as funções mentais que já estão completamente desenvolvidas (resultado de habilidades e conhecimentos adquiridos pelo indivíduo), ou seja, refere-se à capacidade que o indivíduo tem de realizar atividades sozinho. É justamente aí - na distância entre o que já se sabe e o que se pode 
saber com alguma assistência - que reside o segundo nível de desenvolvimento apresentado por Vygotsky, o proximal, que consiste na necessidade que esse indivíduo tem da mediação ou colaboração do outro para avançar na aprendizagem ou ampliar seus conhecimentos.

A seguir, descrevemos as etapas realizadas durante o percurso que percorremos até chegar ao nosso produto final que foi o texto escrito.

\section{a) Escolha do livro a ser lido durante a unidade}

$\mathrm{Na}$ expectativa de oferecer uma outra possibilidade de educação literária aos alunos do segundo ano, consideramos o que é posto pelo programa de língua portuguesa desta turma: estudar a escola literária Realismo (contextos histórico, político e social; o projeto literário, contexto de produção, diálogo desta escola literária com a contemporaneidade etc.). A perspectiva, no entanto, seria outra que não aquela que apresentamos como incômodo de uma prática exercida por muito tempo: tentaríamos criar uma ponte entre o que está posto e o que, de fato, deve ser ensinado. O que desejamos dizer com isso? A forma descontextualizada e superficial com que o tema era tratado seria substituído por um estudo literário que deveria pautar-se no teste "triangular" que Leahy (1999) propunha e que já foi explicitado anteriormente.

Foram apresentadas à turma algumas propostas de leituras de obras clássicas - O mulato, de Aluísio de Azevedo; Memórias póstumas de Brás Cubas e Dom Casmurro, de Machado de Assis; O primo Basílio e O crime do Padre Amaro, de Eça de Queirós - e, após uma mostra do que de mais bonito e interessante elas traziam em seu texto (um resumo com pontos interessantes e curiosos de cada texto, as peculiaridades de seus personagens, espaço e tempo - em que cada uma ocorria) fizemos uma votação em que cada aluno indicaria o livro que desejaria ler. No final, computamos os votos e a obra machadiana Dom Casmurro foi a escolhida.

Pensamos em um prazo para a leitura da obra que possibilitasse aos alunos uma mudança da leitura intensiva para a extensiva ou, usando a metáfora de Francis Bacon, apresentada por Burke (2002), sair do hábito de "engolir" livros para o de "provar" deles. Estabelecemos o prazo de 45 dias, um tempo razoável (tempo limite entre o início da unidade e proximidade com seu término), a fim de que pudéssemos dar conta das outras etapas previstas na proposta.

Considerando que leitores melhoram de leitura em leitura (HARVEY; GOUDIVS, 2008, p. 35), pensamos em sistematizar alguns procedimentos que servissem de conexão para que os alunos construíssem pontes entre o que sabem e a nova informação que encontram nos textos que leem. No dizer de Harvey e Goudivs (2008, p. 40), trata-se de um "ensino responsivo", intencional, flexível e 
adaptativo, uma vez que, tendo um trabalho prévio, o professor, sabendo que os sujeitos se diferenciam, planeja instruções que vão ao encontro de seus interesses e necessidades.

Kleiman (1989 apud GIROTTO; SOUZA, 2010, p. 55) orienta que se deve ofertar situações para que as crianças possam monitorar e ampliar o entendimento, bem como possam adquirir e ativar o seu conhecimento de mundo, linguístico e textual, a partir do que estão lendo. Acreditamos que essa orientação sirva, também, para os jovens, por isso, como estratégia de leitura, pensamos em adotar uma pedagogia de perguntas, ou seja, semanalmente foram indicadas as leituras de um determinado número de capítulos e, posteriormente, em sala de aula, teríamos um tempo (uma aula de 50 minutos) para que os alunos trouxessem suas perguntas sobre o que foi lido e não respostas ao que, supostamente, o professor poderia perguntar sobre os elementos constitutivos do texto (enredo, personagens, tempo, espaço, foco narrativo).

Sobre a adoção de uma pedagogia de perguntas, Harvey e Goudvis (2008, p. 45) dizem:

Perguntas são o coração do ensino e aprendizado. [...]. [...] abrem as portas para o entendimento. Questionar é a estratégia que lança os leitores adiante. Quando os leitores têm perguntas, são menos capazes de abandonar o texto. Leitores proficientes fazem perguntas antes, durante e depois de lerem. Eles perguntam sobre o conteúdo, o autor, as situações, os problemas e as ideias do texto. Nós precisamos comemorar as perguntas das crianças e ajudar a facilitar suas respostas.

Freire (1985) em conversa com Antonio Faundez também traz uma reflexão similar sobre essa questão:

[...] é preciso deixar claro, mais uma vez, que a nossa preocupação pela pergunta, em torno da pergunta, não pode ficar apenas a nível da pergunta pela pergunta. $\mathrm{O}$ importante, sobretudo, é ligar, sempre que possível, a pergunta e a resposta a ações que foram praticadas ou a ações que podem vir a ser praticadas ou refeitas. Eu não sei se fica claro o que digo. Parece-me fundamental esclarecer que a tua defesa e a minha, do ato de perguntar, de maneira nenhuma tornam a pergunta como um jogo intelectualista. Pelo contrário, o necessário é que o educando, ao perguntar sobre um fato, tenha na resposta uma explicação do fato e não a descrição pura das palavras ligadas ao fato. É preciso que o educando vá descobrindo a relação dinâmica, forte, viva, entre palavra e ação, entre palavra-ação-reflexão. Aproveitando-se, então, exemplos concretos da própria experiência dos alunos durante uma manhã de trabalho dentro da escola, no caso de uma escola de crianças, estimulá-los a fazer perguntas em torno da sua própria prática e as respostas, então, envolveriam a ação que provocou a pergunta. Agir, falar, conhecer estariam juntos.

Foi, assim, na perspectiva de possibilitar que os alunos ampliassem sua capacidade de compreensão leitora em relação ao texto por eles explorado, que a adoção da pedagogia da pergunta 
como uma situação desafiadora foi bastante pertinente às demais etapas que executaríamos em relação ao trabalho proposto para esta turma.

\section{b) Análise e contextualização da obra}

Passado o tempo estabelecido para a leitura do romance Dom Casmurro, realizamos a análise da obra. Fizemos uma roda de conversa e os alunos trouxeram, agora, suas indagações gerais após a realização da leitura completa. Indagações do tipo "E aí, professora, traiu ou não traiu? Fiquei na dúvida!” ou “Ah, professora! Se é ele quem conta a história, claro que vai colocar a culpa em Capitu, se, desde o começo, ele disse que ela era dissimulada! Não é verdade?”.

O momento foi recheado de perguntas, comentários, comparações. Acredito que a estratégia - pedagogia de perguntas ao longo de todo processo de leitura - foi muito enriquecedor para uma melhor compreensão do lido, pois muitos foram os comentários e perguntas que surgiram. Falamos sobre o contexto de produção da obra, sobre a caracterização das personagens e a relevância de cada uma para a obra, além da análise do enredo (fatos mais marcantes, relação da obra com o projeto literário do período em que ela foi produzida).

Como comentava Jonathan Swift com seu costumeiro humor pessimista (apud BURKE, 2002, p. 179), "entrar no palácio do conhecimento pelo portão principal exige um consumo de tempo e formalidades. Gente muito apressada e pouco cerimoniosa se contenta com entrar pela porta dos fundos". Nossos meninos e meninas entraram pela porta da frente!!!

\section{c) Apresentação da proposta de retextualização}

Após a leitura e a discussão da obra lida, lançamos para a turma a proposta de retextualização. Revelava-se, ali, outro objetivo para esta atividade: serviria ela não só para confrontá-la com seu contexto de produção, mas, principalmente, para servir de pretexto e de motivação (por que não?!) para a prática de tantas outras escritas, para o encontro com tantos outros gêneros discursivos e suas peculiaridades.

Os alunos, tendo em vistas as múltiplas possibilidades de produção que lhes foram sugeridas, organizaram-se em grupo para:

- decidir qual gênero discursivo seria eleito pelo grupo para a realização da atividade de retextualização;

- fazer leituras de textos pertencentes ao gênero escolhido, a fim de que pudessem apropriar-se, ainda mais, de suas peculiaridades, considerando alguns aspectos importantes, tais como: suas características de situação de produção (quem são os 
interlocutores e em que papel social se encontram; quais contextos e tempos de produção e circulação; quais objetivos, tipos de linguagem etc.); seus aspectos tipológicos (a construção composicional característica do gênero) e as capacidades de linguagem dominantes requeridas por eles.

\title{
d) Produção das atividades de retextualização
}

Os alunos produziram seus textos que, após análise do professor, passaram pelo processo de reescrita, para, assim, serem apresentados à turma e, posteriormente, publicados na biblioteca do IFBA, campus Eunápolis.

\section{e) Rede de trocas}

Agendamos a sala de línguas do IFBA Campus Eunápolis e promovemos uma tarde literária. Como a sala é pequena, participaram apenas os alunos da própria turma. Ali, os alunos apresentaram sua produção, compartilharam e fortaleceram seus conhecimentos acerca dos gêneros vistos.

A seguir, apresentamos as produções escritas dos alunos, resultado da proposta de retextualização:

\author{
TEXTO 1 \\ Dom Casmurro \\ (Grupo A) \\ Bentinho, Dom Casmurro passou a ser \\ Órfão de pai foi criado por sua mãe \\ Que a todo custo o queria proteger \\ Com muito carinho, Bentinho foi criado \\ Por Justina, Tio Cosme, José Dias \\ e Dona Glória \\ Sempre fora estimado \\ Até que um dia \\ Para cumprimento de uma promessa \\ Seu destino foi mudado \\ Bentinho então seguiria para o seminário \\ Ser padre não era sua vocação \\ Capitu, por sua vez \\ tomou o seu coração \\ Dona Glória triste iria ficar \\ Por seu único filho \\ Ter que a deixar \\ Bentinho o seminário abandona \\ Com ajuda de José Dias \\ Um escravo o seu lugar toma \\ Correm os anos e com ele o amor \\ A aliança entre Bentinho e Capitu \\ O tempo não quebrou
}


Passou-se o namoro

E o casamento chegou

E nesse meio tempo

Bentinho em Direito se formou

Muito amigo de Escobar ele fica

Que se casa com Sancha

De Capitu, ela era amiga

Do casamento de Bentinho e Capitu

Nasce Ezequiel

E o amigo Escobar

Morre e vai para o céu

Durante o enterro

Nasce uma desconfiança cruel

Tamanha dor sentida por Capitu

Para com seu amigo fiel

A partir de então

O ciúme só cresce

E Ezequiel, cada vez mais

Com seu amigo se parece

Tomado pela raiva

Um assassinato Bentinho começou a planejar

Sua vida, de sua esposa e filho

Bentinho pensa em tirar

Por conta dos ciúmes

Seu grande amor

Teve que deixar

Capitu e Ezequiel

Viajam para Europa

Onde anos depois

A mulata bate as botas

Ezequiel já moço

Ao Brasil volta

E sua semelhança com Escobar

A Bentinho traz revolta

Ezequiel volta para o lar

Até sua vida perder

E Bentinho, agora Dom Casmurro

Imensa angústia

Passa a sentir no peito

Será então que um dia

Seu grande amor

Veio a traí-lo mesmo?

TEXTO 2

Lembranças Amarguradas

(Grupo B)

$\mathrm{Na}$ infância inocente

Bento e Capitu vivem a brincar

Dessa união envolvente

Vem um sentimento a brotar

Num muro riscado

Se esconde uma declaração

Entre uma trança e outra

Um beijo surge então

Com a promessa do seminário

Tudo se põe a perder 
Preocupados com a separação

Arranjam um jeito de essa situação reverter

Prometeram se casar

E ele teve que partir

No seminário a morar

Amigou-se com Escobar

Um imprevisto aconteceu

Bentinho teve que voltar

D. Glória adoeceu

Sua família conheceu Escobar

Abandonando o seminário

Os dois amigos se separaram

Cada um foi para o seu lado

Depois de cinco anos eles se reencontraram

Escobar casou-se com Sancha

Amiga, quase irmã de Capitu

Eles tiveram uma menina

E a chamaram de Capitolina

Capitu e Bento se casaram

E queriam ter um filho

Durante muito tempo tentaram

Até que um dia conseguiram

O menino recebeu o nome de Ezequiel

Em homenagem ao outro casal

Bentinho cismado percebeu a semelhança

Com seu velho amigo

Pensou em matar a sua criança

Passando a vida amargurado

Com tanta desconfiança

Eles se divorciaram

E acabou a esperança

Bentinho não era mais o mesmo

E agora era Dom Casmurro

Escreveu um livro inútil

Mas prefere falar dos Subúrbios

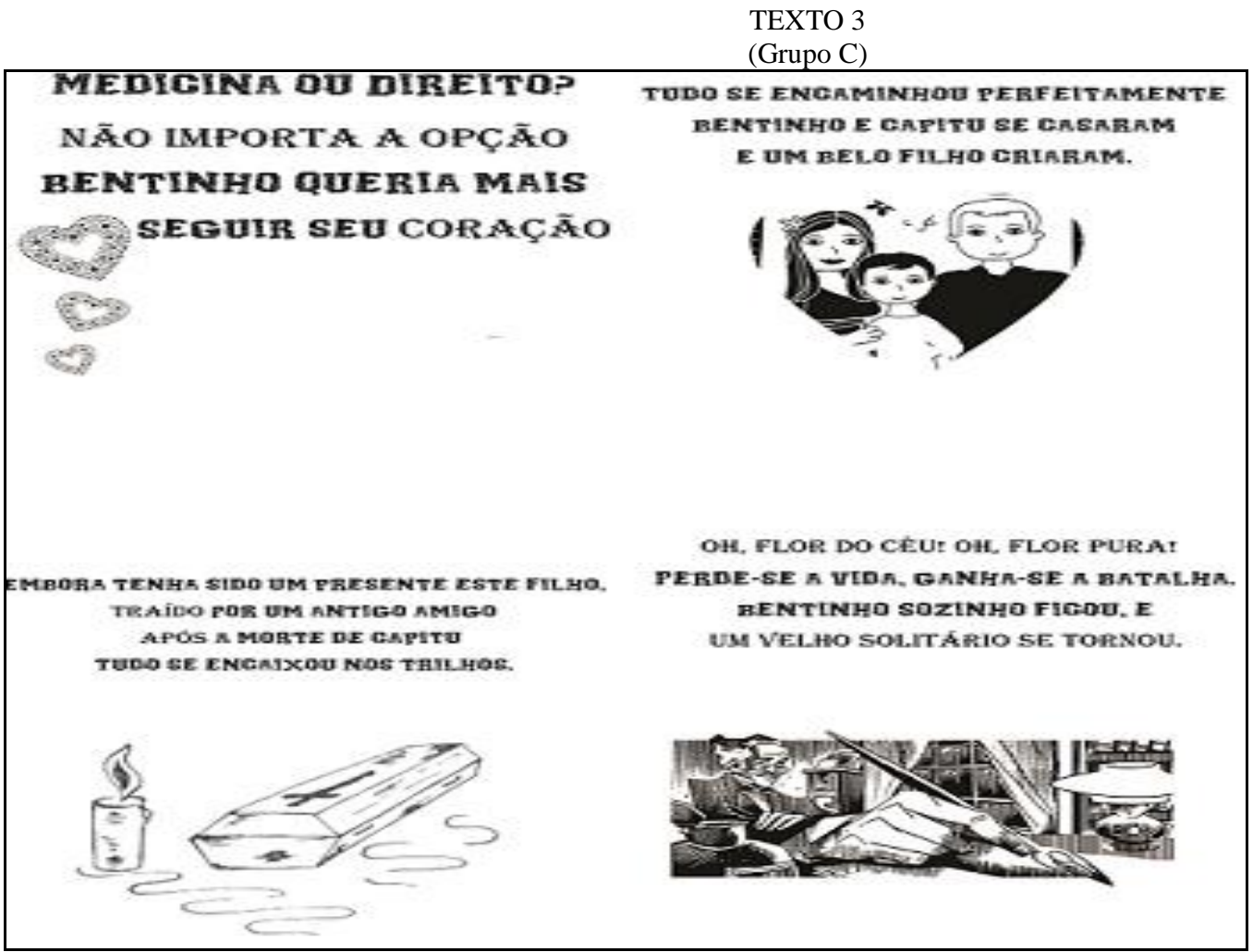

Teias v. 18 • n. 49 • 2017(abr./jun.): Ensino de língua materna no ensino médio 


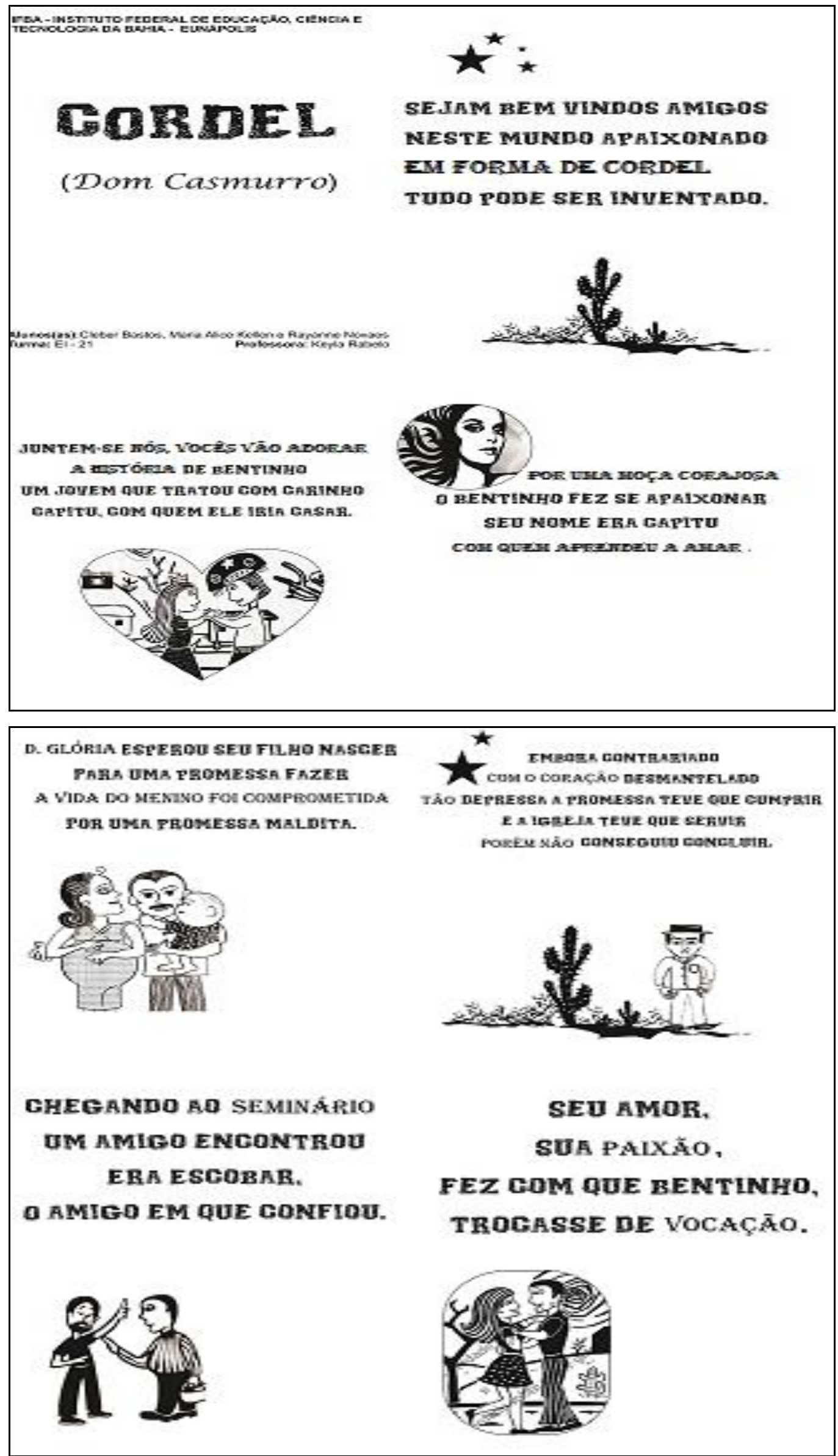


TEXTO 4

(Grupo D)

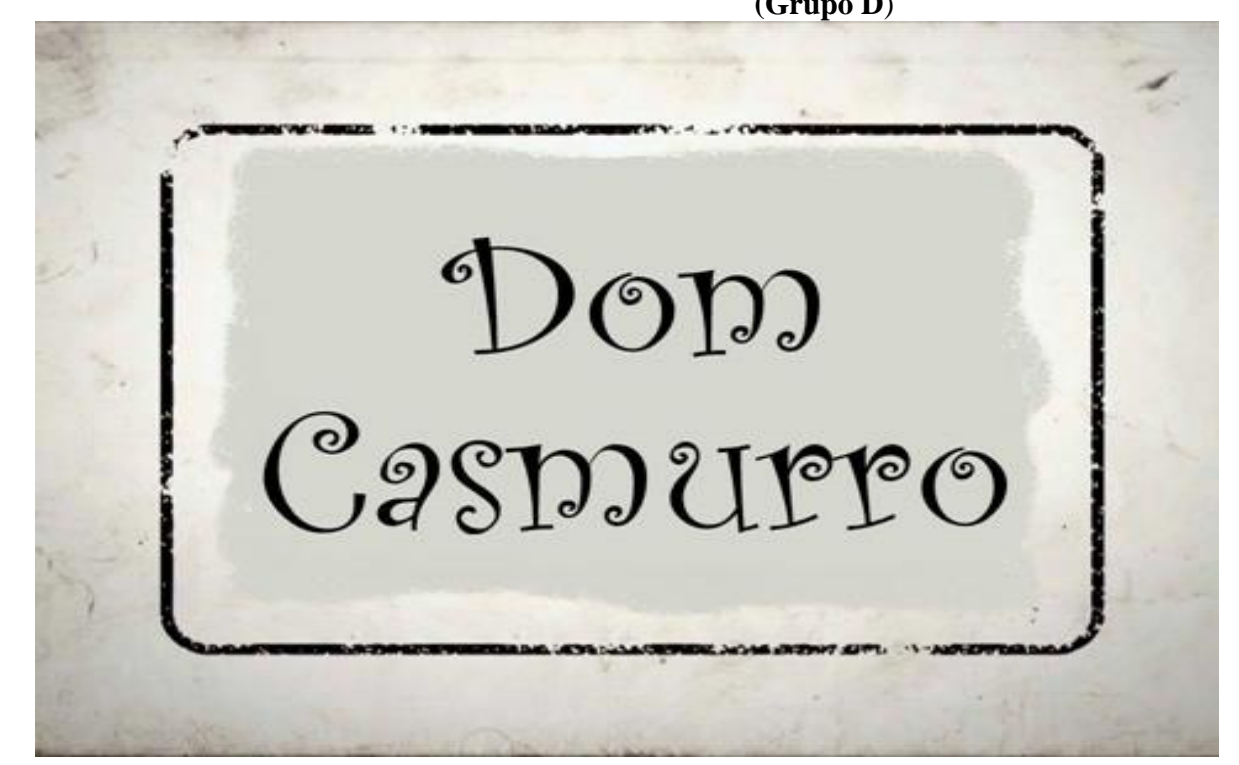

Esse é bentinho, mais conhecido como "Dom Casmurro", o protagonista dessa suprendente história que começa pouco depois dele nascer:

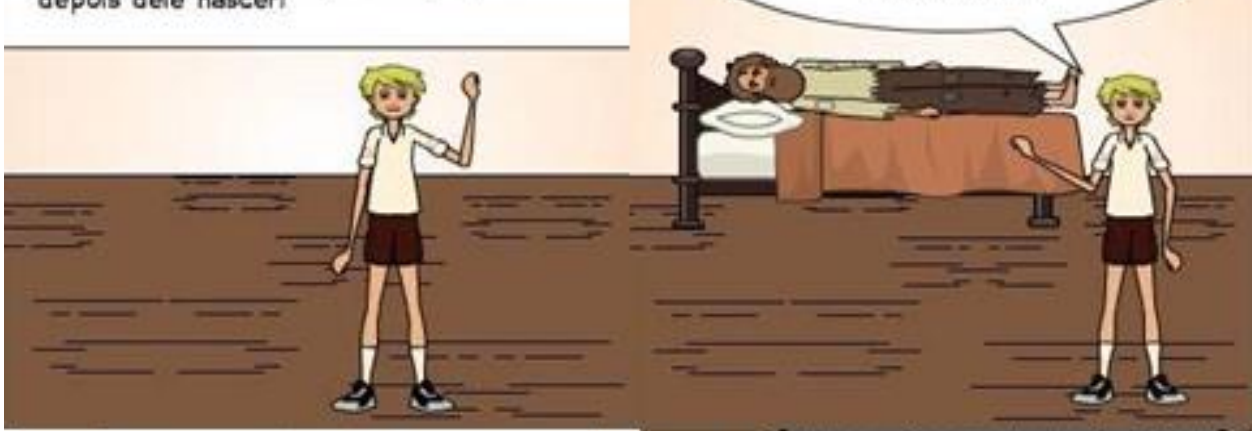

Meu nome é Jose Dias. Estava passando pela Regiaso e flquei sabendo de um certo Senhor que estava padecendo. Creio que posso ajudar...

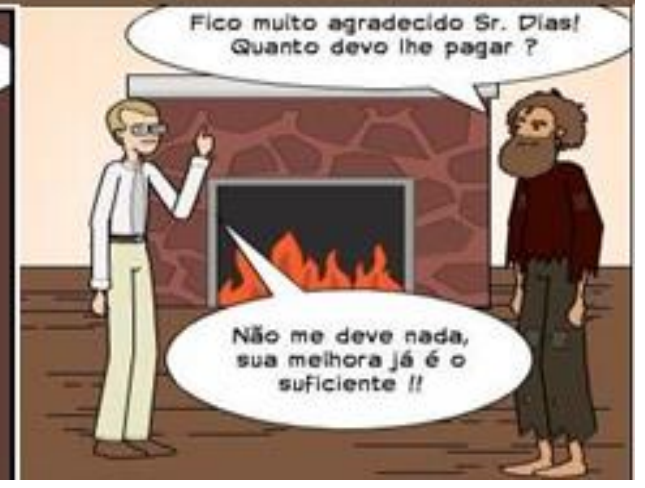



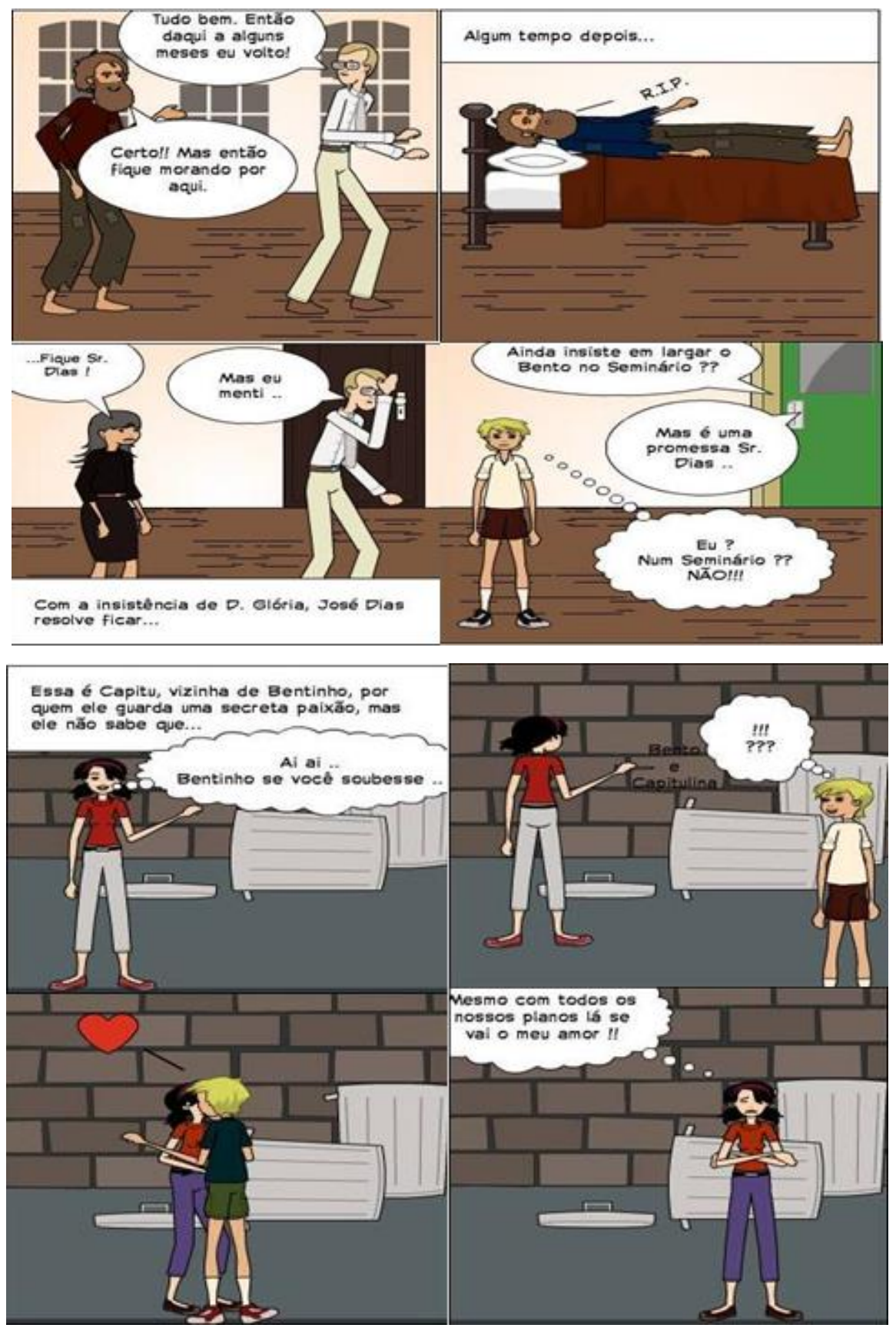

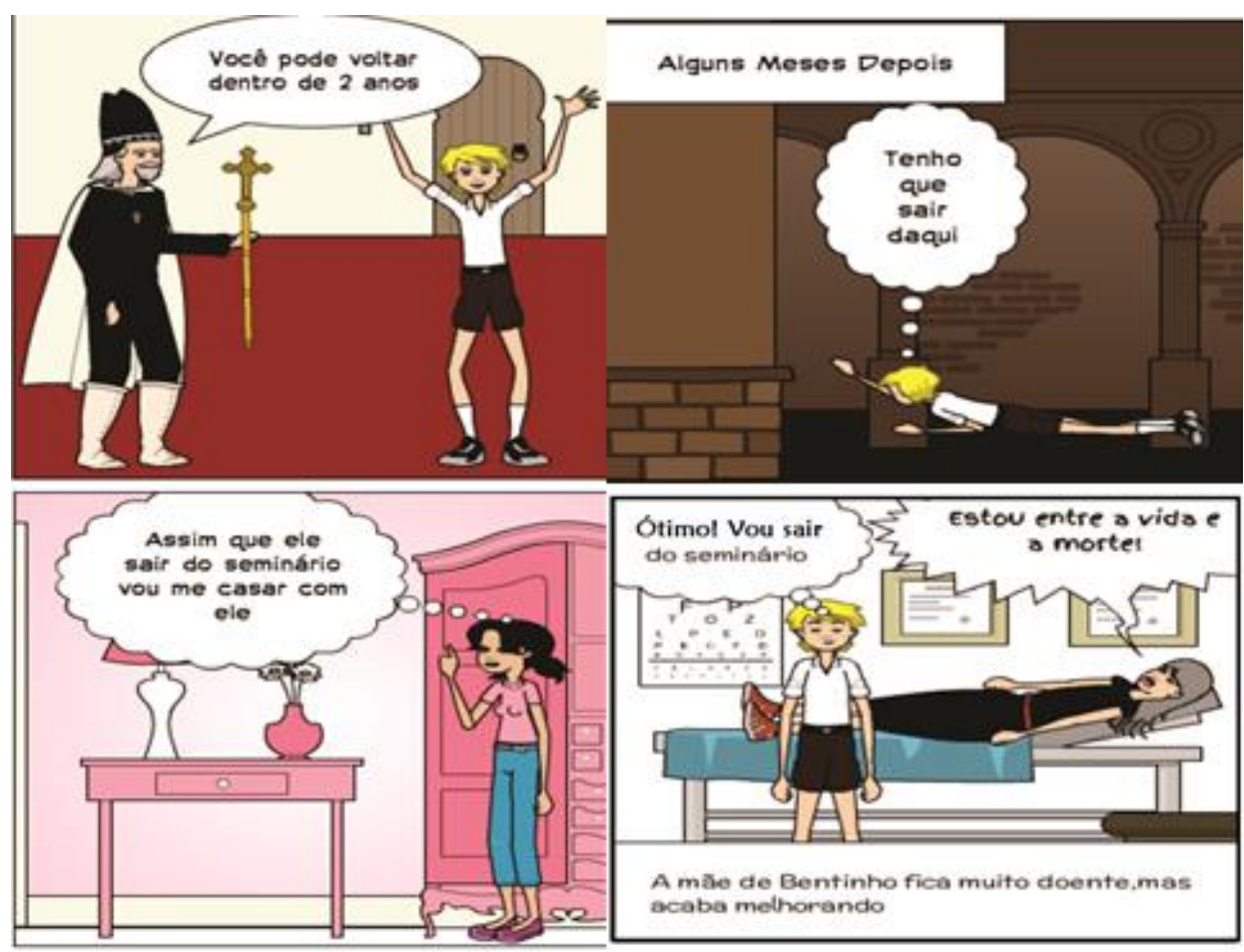

\section{Bentinho conhecev Escobar, um amigo que encontrou no seminario \\ Bentinho nāo agDentava mais ficar no seminario ele teria que sair dall de qualquer jeito}

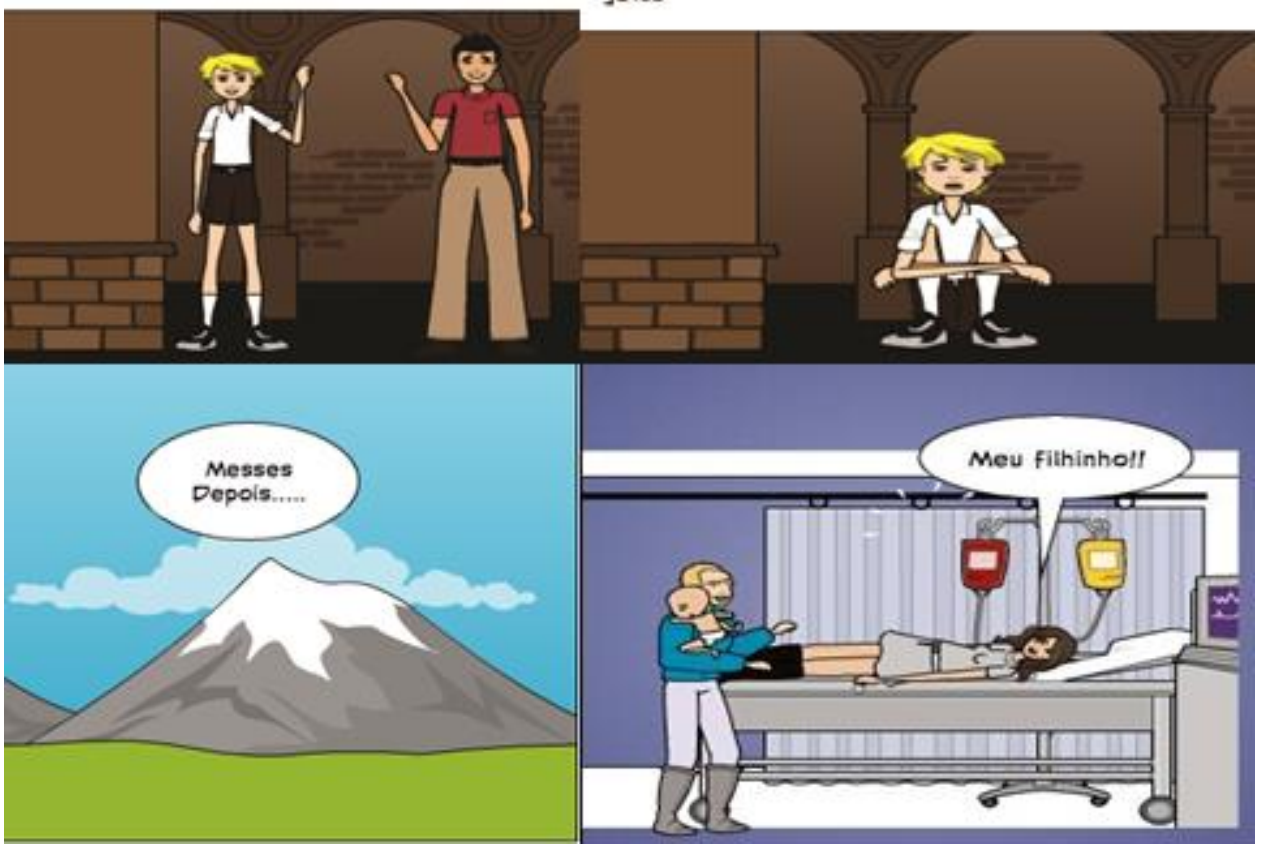



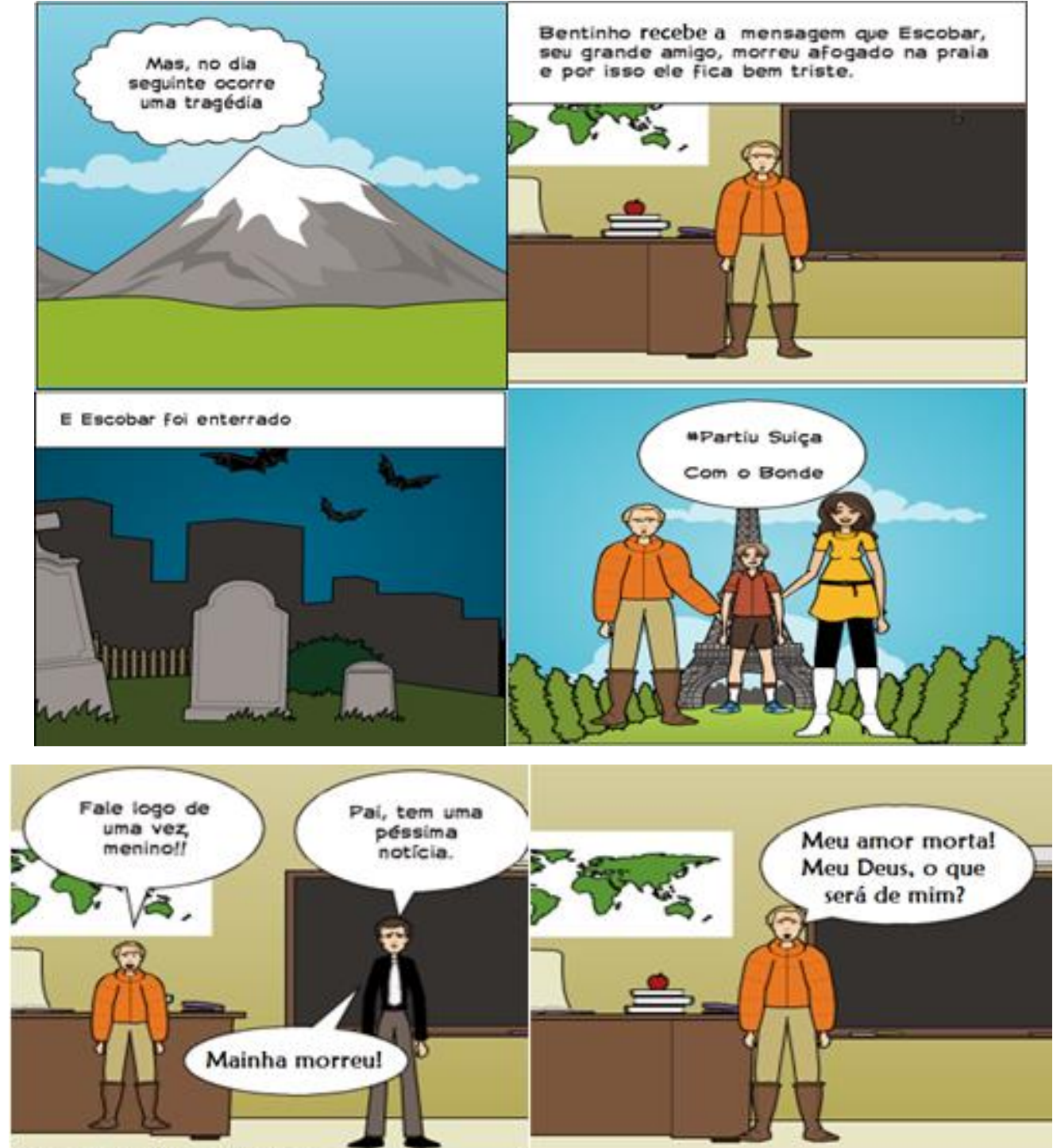

Ezequiel voltou da Suíça já grande e formado em arqueologia. Já estava de partida para o Oriente Médio.
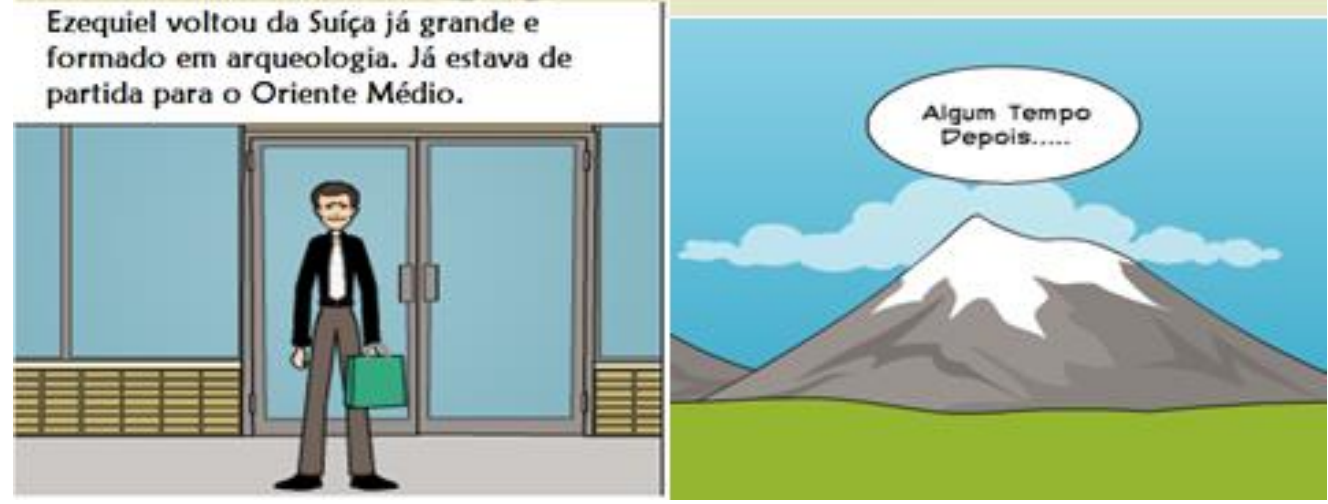


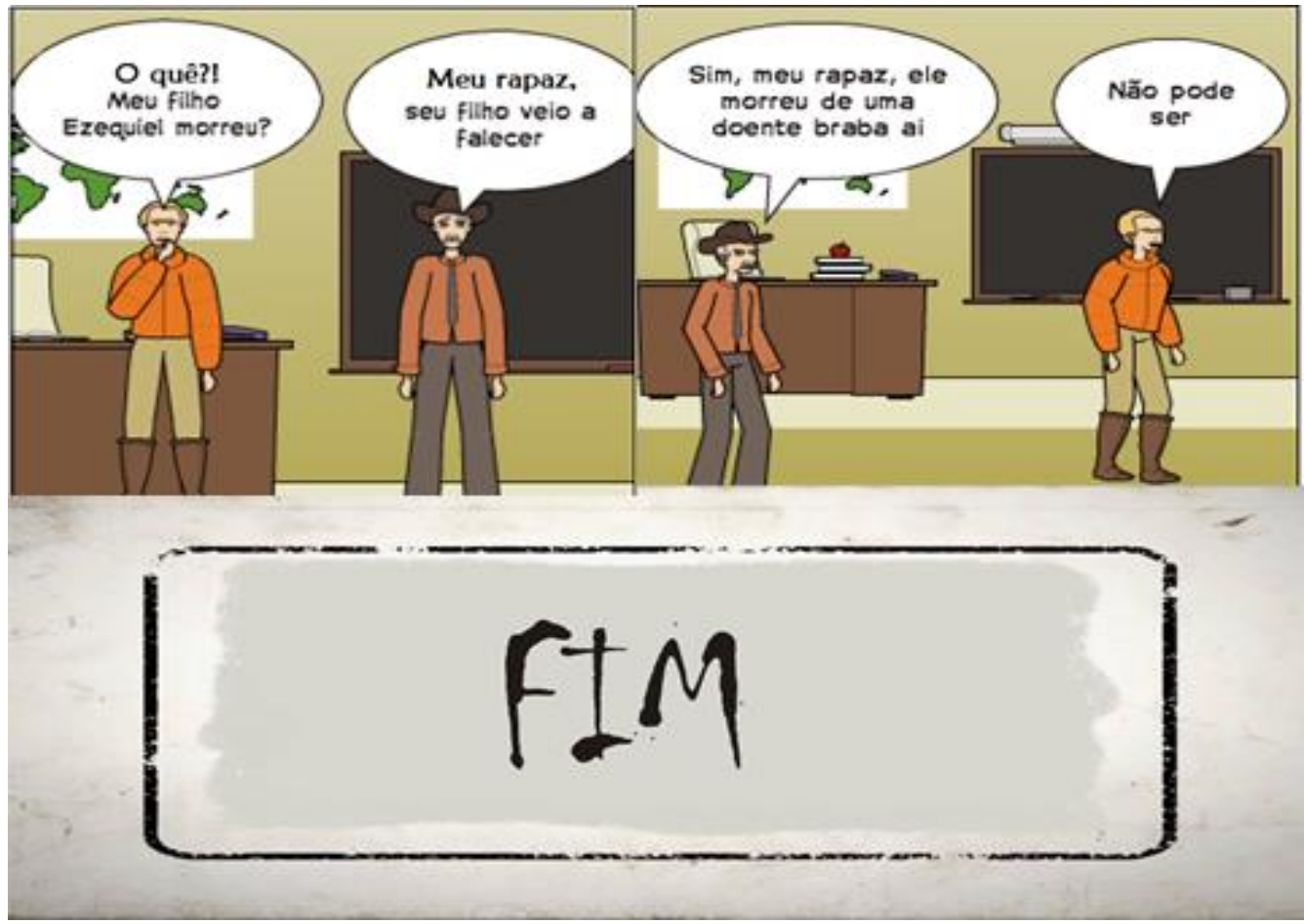

Quando os grupos produtores dos textos I e II optaram pela retextualização do romance Dom Casmurro em forma de poema, um tipo de composição estruturada em versos, de tamanho muito variado (COSTA, 2012, p. 191), eles, antes de chegarem ao processo de produção escrita, fizeram uma busca das características desse gênero, por sinal bastante variáveis, visto que a presença do ritmo, divisão em estrofes, a rima e outros aspectos nem sempre são frequentes em sua estruturação.

A mesma orientação - o olhar atento às características dos gêneros - foi dada aos grupos que decidiram usar, no processo de transposição de gêneros, a História em quadrinhos e a Literatura de Cordel: era necessária a leitura de outros textos pertencentes aos gêneros em questão a fim de que pudessem perceber suas especificidades (organização estrutural, jogos linguísticos, suporte portador em que aparecem com frequência, possíveis interlocutores etc.).

\section{f) Publicação das produções}

Os textos produzidos pelos alunos foram digitalizados, organizados em um CD intitulado Dom Casmurro: uma motivação e vários textos. O material foi disponibilizado na biblioteca da escola para que outros alunos tenham acesso ao material.

Interessante destacar, aqui, que, mesmo antes da publicação na biblioteca (isso não foi logo de imediato, pois alguns textos precisaram passar por mais um processo de reescrita), os textos 
foram publicizados pelos alunos em suas redes sociais ou, como no caso do Cordel feito em forma de filme, disponibilizado no Youtube. ${ }^{1}$

\section{CONSIDERAÇÕES FINAIS}

Nota-se que a variedade de gêneros povoou as escolhas entre os grupos de trabalho História em Quadrinhos (HQ), Poemas e Literatura de Cordel, o que tornou possível não só a exploração de algumas regularidades nas esferas sociais em que esses gêneros são utilizados, como também criou oportunidades de os alunos vivenciarem letramentos diversos, algo fundamental para que eles se apoderem desses conhecimentos e sejam capazes de se assumirem enquanto sujeitos do seu discurso, o que significa saber trazer para seu texto, de forma adequada e crítica as diferentes vozes que circulam histórica e socialmente, ainda que seja para funcionarem como argumentos de autoridade, seja para refutá-los.

Encontramos, nas palavras de Dell'Isola (2007, p. 25), apoio para o que acabamos de afirmar como práticas de linguagem concretas:

Os alunos devem se preparar para compreender a dinâmica dos gêneros que circulam na sociedade e estarem aptos a interagir com a escrita a que estão familiarizados e com que não lhes é familiar, dada a dinamicidade do discurso.

Como visto, todas as propostas fundamentaram-se sobre o postulado de um ensino sistematizado e articulado em forma de sequência didática. Dolz e Schneuwly fazem a seguinte observação sobre a importância desse tipo de trabalho:

As estratégias de ensino supõem a busca de intervenções no meio escolar que favoreçam a mudança e a promoção dos alunos a uma melhor maestria dos gêneros e das situações de comunicação que lhes correspondem. Trata-se, fundamentalmente, de se fornecerem aos alunos os instrumentos necessários para progredir. Para fazê-lo, as atividades comunicativas complexas que os alunos ainda não estão aptos a realizar de maneira autônoma serão, de certa maneira, decompostas, o que permitirá abordar um a um, separadamente, os componentes que colocam problemas para eles. (DOLZ; SCHNEUWLY, 2004, p. 45)

Buin-Barbosa (2013, p. 195), sobre a mixagem de práticas de escrita com a qual estes alunos estiveram envolvidos, mencionou:

[...] Diante de um gênero específico, qualquer que seja ele, o importante será o aluno conseguir, nas várias escritas, orientações e reescritas, mobilizar diferentes conhecimentos para poder adequar/ modificar seu modo de dizer em função desse gênero, da situação da qual ele

\footnotetext{
${ }^{1}$ O Cordel em linguagem fílmica encontra-se disponível em: 〈https://www.youtube.com/watch?v=JOCVcICCiWI〉.
} 
emerge. E parece que a habilidade de ficcionalizar, em muitos casos, tem funcionado como base para isso.

Essas e tantas outras reflexões - concepções de língua, de texto, de ensino de língua portuguesa, de orientação metodológica (sequências didáticas) para a estruturação da pedagogia da escrita na sala de aula - em consonância com o encontro estabelecido com os teóricos com os quais nos aliamos ao longo da pesquisa, serviram para nos indicar que, incansavelmente, devemos combater todas as pedagogias de escrita que se configuram como portas-contra a escrita do aluno.

\section{REFERÊNCIAS}

ASSIS, M. de. Dom Casmurro. In: Obras completas. Rio de Janeiro: Nova Aguilar, 1994. v. 1. Não paginado. Disponível em: <http://machado.mec.gov.br/images/stories/pdf/romance/marm08.pdf>. Acesso em: 16 jun. 2014.

BAZERMAN, C. Gêneros textuais, tipificação e interação. 4. ed. Trad.: Judith Chambliss Hoffnagel. São Paulo: Cortez, 2011.

BUIN-BARBOSA, E. Mixagem de práticas de escrita na escola. In: GONÇALVES, A. V; BAZARIM, M. (Org.). Interação, gêneros e letramento: a (re)escrita em foco. 2. ed. Campinas, SP: Pontes, 2013.

BURKE, P. Problemas causados por Gutenberg: a explosão da informação nos primórdios da Europa moderna. Estudos Avançados, São Paulo, v. 16, n. 44, p. 173-185, jan./abr. 2002. Disp.: <http://www.scielo.br/scielo.php?pid=S010340142002000100010\&script=sci_arttext>. Acesso em: 15 maio 2014.

COLOMER, T. Andar entre livros: a leitura literária na escola. Tradução de Laura Sandroni. São Paulo: Global, 2007.

COSTA, S. Roberto. Dicionário de gêneros textuais. 3. ed. Belo Horizonte: Autêntica, 2012.

DELL'ISOLA, R. L. P. Retextualização de gêneros escritos. Rio de Janeiro: Lucerna, 2007.

DOLZ, J.; NOVERRAZ, M; SCHNEUWLY, B. Sequências didáticas para o oral e a escrita: apresentação de um procedimento. In: SCHNEUWLY, B. et al. Gêneros orais e escritos na escola. Trad.: Roxane Rojo e Glais Sales Cordeiro. Campinas, SP: Mercado das Letras, 2004. p. 95-128.

FARACO, C. A. As sete pragas do ensino de português. In: GERALDI, J.W. (Org.). O texto na sala de aula: leitura e produção. 3. ed. Cascavel: Assoeste, 1984. p.17-23.

FREIRE, P. Por uma pedagogia da pergunta. 4. ed. Rio e Janeiro: Paz e Terra, 1985. (Educação e Comunicação: v. 15). Não paginado. Disp.: <http://www.dhnet.org.br/direitos/militantes/paulofreire/paulo_freire_por_uma_pedagogia_ da_pergunta.pdf>. Acesso em: 6 jun. 2013.

GERALDI, J. W. A aula como acontecimento. São Carlos, SP: Pedro \& João, 2010.

Portos de passagem. 4. ed. São Paulo: Martins Fontes, 1997.

GIROTTO, C.; SOUZA, R. Estratégias de leitura: para ensinar alunos a compreenderem o que leem. In: SOUZA, R. (Org.) Ler e compreender: estratégias de leitura. Campinas, SP: Mercado de Letras, 2010. p. 45-114.

HARVEY, S.; GOUDVIS, A. Strategies that work: teaching comprehension for understanding and engagement. 2. ed. Portland, Me; Markham, Ont.: Pembroke Publishers, 2008.

KOCH, I. G. V. Desvendando os segredos do texto. 5. ed. São Paulo: Cortez, 2006.

O texto e a construção dos sentidos. 9. ed. São Paulo: Contexto, 2007.

; ELIAS, M. V. Ler e escrever: estratégias de produção textual. 2. ed. São Paulo: Contexto, 2010.

LEAHY, C. Leitura no final do século XIX: um caso de controle pedagógico. In: LYONS, M. A palavra impressa: histórias da leitura no XIX. Tradução Cyana Leahy. Rio de Janeiro: Casa da Palavra, 1999. p. 89-113.

MACHADO, A. R. Revisitando o conceito de resumos. In: DIONÍSIO, A. P.; MACHADO, A. R.; BEZERRA, M. A. (Org.). Gêneros textuais e ensino. Rio de Janeiro: Parábola, 2010. p. 149-162. 
MARCUSCHI, L. A. Da fala para a escrita: atividades de retextualização. 8. ed. São Paulo: Cortez, 2007.

Gêneros textuais: configuração, dinamicidade e circulação. In.: KARWOSKI, A. M.; GAYDECZKA, B.; BRITO, K. S. (Org.). Gêneros textuais: reflexões e ensino. 4. ed. São Paulo: Parábola, 2011. p. 17-31.

MARTINS, M. H. (Org.). Questões de linguagem. 6. ed. São Paulo: Contexto, 2001. (Coleção Repensando o Ensino)

ORLANDI, E. P. Discurso e texto: formação e circulação dos sentidos. 4. ed. Campinas, SP: Pontes, 2012.

SCHNEUWLY, B.; DOLZ, J. Os gêneros escolares: das práticas de linguagem aos objetos de ensino. Tradução de Glais Sales Cordeiro. In: et al. Gêneros orais e escritos na escola. Tradução e organização de Roxane Rojo e Glais

Sales Cordeiro. Campinas, SP: Mercado das Letras, 2004. p. 35-60.

; NOVERRAZ, M. Sequências didáticas para o oral e a escrita: apresentação de um procedimento.

Tradução de Glais Sales Cordeiro. In: et al. Gêneros orais e escritos na escola. Tradução e organização de Roxane Rojo e Glais Sales Cordeiro. Campinas, SP: Mercado das Letras, 2004. p. 95-128.

ZABALA, A. A prática educativa: como ensinar. Tradução de Ernani F. da Rosa. Porto Alegre: Artmed, 1998.

\section{RESUMO}

O presente artigo objetiva ampliar a discussão sobre as práticas de escrita realizadas no ensino médio, como também compartilhar uma experiência de estudo dos gêneros textuais a partir da proposta de retextualização organizada conforme o modelo de Sequência Didática (SD) sugerido por Dolz e Schneuwly (2004). A atividade permitiu que os alunos ampliassem seu conhecimento em relação às questões que envolvem a educação literária e a educação linguística. Os resultados nos mostram que a escola, espaço responsável em promover situações de prática de produção de texto, precisa buscar, permanentemente, a atualização de seu repertório teórico/metodológico e da atitude política ali engendrada a fim de que aos alunos se tornem, a partir do conhecimento e da apropriação dos diversos gêneros textuais disponíveis em nossa sociedade, competentes usuários da língua.

Palavras-chave: Produção escrita de texto. Retextualização. Gêneros textuais.

\section{ADVENTURES WITH WRITING IN MIDDLE SCHOOL: RETEXTUALIZATION AS A TEXTUAL PRODUCTION PROPOSAL}

\section{SUMMARY}

The present article aims to broaden the discussion about writing practices carried out in High School, as well as to share an experience of study of textual genres based on the proposed retextualization organized according to the Didactic Sequence (SD) model suggested by Dolz and Schneuwly (2004). The activity allowed the students to broaden their knowledge regarding issues involving literary education and language education. The results show us that school, a space responsible for promoting situations of text production practice, must permanently seek to update its theoretical/methodological repertoire and the political attitude it engenders in order that students through the knowledge and appropriation of the different textual genres available in our society, competent users of the language.

Keywords: Written text production. Retextualization. Textual generes. 